\title{
MODUL IPA TERPADU BERBASIS INQUIRY LEARNING PADA MATERI ZAT ADITIF MAKANAN UNTUK MENINGKATKAN KETERAMPILAN PROSES SAINS
}

\author{
Siti Patimah"); Tiurlina Siregar ${ }^{2)}$; Albert Lumbu ${ }^{3)}$ \\ ${ }^{1)}$ SMP Negeri 1 Sentani; sitip736@gmail.com \\ ${ }^{2)}$ Program Studi Magister Pendidikan IPA, UNCEN; tiurlina.siregar@yahoo.com \\ ${ }^{3)}$ Program Studi Magister Pendidikan IPA, UNCEN; albertlumbu@gmail.com
}

\begin{abstract}
This study aims to find out how to make an integrated science module, develop an integrated science module, and improve science process skills by using an integrated science module based on inquiry learning on food additives. Research Methods Research and Development. The research sample was conducted in class VIII A SMP Negeri 1 Sentani with a total of 32 students. The results showed that: 1) How to make a module through seven stages, namely module needs analysis, module design, implementation, assessment, evaluation, validation and quality assurance of the module, using four module components, namely the opening, introduction, learning and evaluation. 2) The development of an integrated science module based on inquiry learning on food additives material through the arrangement of stages of making modules for the use of the school environment Very feasible category to be used as teaching material and 3) Assessment of students' science process skills in RPP 1 to RPP 3 learning produces an average percentage of $69.75 \%$ with the skilled category.
\end{abstract}

Keywords: Science Module; Inquiry Learning; Science Process Skills

\begin{abstract}
ABSTRAK
Penelitian ini bertujuan untuk mengetahui bagaimana cara membuat modul IPA terpadu, kelayakan pengembangan modul IPA terpadu, dan peningkatan keterampilan proses sains dengan menggunakan modul IPAterpadu berbasis inquiry learning pada materi zat aditif makanan. Metode Penelitian Research and Development. Sampel penelitiandilaksanakan di kelas VIII A SMP Negeri 1 Sentani dengan jumlah 32 peserta didik. Hasil penelitian menunjukkan bahwa : 1) Cara membuat modul melalui tujuh tahap yaitu analisis kebutuhan modul, mendesain modul, implementasi, penilaian, evaluasi, validasi dan jaminan kualitas modul, dengan menggunakan empat komponen modul yaitu bagian pembuka, pendahuluan, pembelajaran dan evaluasi. 2) Kelayakan modul IPA terpadu berbasis inquiry learning pada materi zat aditif makanan diperoleh rata-rata kelayakan modul IPA sebesar 94,76\% dengan kategori sangat layak digunakan sebagai bahan ajar dan 3) Penilaian keterampilan proses sains peserta didik pada pembelajaran RPP 1 sampai RPP 3 menghasilkan rata-rata persentase sebesar $69,75 \%$ dengan kategori terampil.
\end{abstract}

Kata Kunci : Modul IPA; Inquiry Learning; Keterampilan Proses Sains

\section{PENDAHULUAN}

Pendidikan yang berdasarkan

Pancasila dan Undang-undang Dasar

Negara Republik Indonesia Tahun 1945, merupakan usaha yang dilakukan agar manusia dapat mengembangkan potensi dirinya melalui proses pembelajaran yang dikenal dan diakui oleh masyarakat. 
Undang-Undang Dasar Negara Republik Indonesia Tahun 1945 pasal 31 ayat (1) menyebutkan bahwa setiap warga negara berhak mendapat pendidikan, dan ayat (3) menegaskan bahwa pemerintah mengusahakan dan menyelenggarakan satu sistem pendidikan nasional meningkatkan ketakwaan, keimanan dan akhlak mulia dalam rangka mencerdaskan kehidupan bangsa yang diatur dengan undangundang, untuk itu seluruh komponen bangsa wajib mencerdaskan kehidupan bangsa yang merupakan salah satu tujuan negara Indonesia, sebagaimana tercantum dalam undang-undang nomor 20 tahun 2003 tentang Sistem Pendidikan Nasional (Depdiknas, 2013). Sistem pendidikan nasional adalah suatu strategi atau cara yang akan dipakai untuk melakukan proses belajar mengajar dalam mencapai tujuan agar para pelajar tersebut dapat secara aktif dan saling terkait serta terpadu untuk mencapai tujuan pendidikan nasional dalam pemerataan kesempatan pendidikan.

Isi kurikulum 2013 menyatakan bahwa adanya perkembangan IPTEK dan membangun rasa ingin tahu peserta didik secara tepat dan maksimal (Kemendikbud, 2013).

Menurut Gulo dalam Huda (2018) strategi pembelajaran inkuiri berarti suatu rangkaian kegatan belajar yang melibatkan secara maksimal seluruh kemampuan peserta didik untuk mencari dan menyelidiki secara sistematis, kritis, logis, analitis, sehingga peserta didik dapat merumuskan hipotesis penemuannya dengan percaya diri. Inkuiri merupakan bagian inti dari kegiatan pembelajaran berbasis kontekstual, sehingga pengetahuan dan keterampilan yang diperoleh peserta didik diharapkan bukan hasil mengingat seperangkat fakta melainkan hasil dari menemukan sendiri.

Dalam kehidupan sehari-hari zat aditif makanan tidak asing lagi bagi peserta didik, selain itu materi zat aditif bahan makanan merupakan salah satu materi IPA kimia untuk SMP/MTs kelas VIII pada kurikulum 2013. Materi zat aditif memuat submateri pewarna, pemanis, pengawet, dan penyedap. Zat aditif berupa pewarna, pemanis, pengawet, dan penyedap dapat digolongkan secara alami dan sintetis (buatan). Bahan aditif alami, sebagian besarnya adalah yang berasal dari tumbuhan, hal ini sejalan dengan beberapa penelitian yang telah dilakukan sebelumnya tentang pemanfaatan tumbuhan sebagai zat aditif (Andriani, Masriani, \& Muharini, 2019).

Penggunaan modul diharapkan dapat mengatasi kesulitan yang dihadapi guru dalam mencapai tujuan pembelajaran materi IPA, kesulitan mencapai tujuan pembelajaran kemungkinan disebabkan oleh : (1) Input peserta didik rendah, (2) Guru kurang aktif mengembangkan bahan ajar yang disesuiakan dengan metode pembelajaran serta karakteristik pesrta 
Jurnal Ilmu Pendidikan Indonesia 9 (2) : 61 - 67 | 63

didik, (3) rendahnya motivasi belajar peserta didik, (4) pembelajaran masih menggunakan pola terpusat pada guru dan berorentasi pada pencapaian nilai ujian yang baik, namun bukan pembelajaran yang memberikan pengalaman belajar kepada peserta didik, sehingga aktivitas pembelajaran cenderung bersifat hafalan yang menyebabkan kemampuan peserta didik sangat lemah, dan cenderung menghafal rumus dari pada memahami konsep, sehingga peserta didik menjadi pasif dalam kegiatan pembelajaran.

Berdasarkan pengalaman dan observasi penulis, materi IPA terpadu zat aditif makanan yang dianggap mudah dipahami oleh peserta didik dan konsep berkaitan dalam kehidupan sehari-hari tidak perlu lagi diajarkan sesuai dengan prosedur yang ada atau hanya biasa diberikan penugasan saja karena dianggap mudah. Namun kenyataannya banyak peserta didik belum memahaminya, tanpa melalui praktikum atau demontrasi di depan kelas tentang materi tersebut. Disini peserta didik hanya menghafal tanpa mengetahui konsep dasarnya, sehingga peserta didik mengalami kesulitan menghadapi soal yang diberikan oleh guru. Motivasi belajar peserta didik yang rendah lebih memperburuk hasil belajar peserta didik. Materi zat aditif makanan memiliki KKM 70, namun kenyataannya nilai peserta didik untuk materi tersebut lebih dari 50\% masih berada di bawah KKM, jika dilihat dari hasil ulangan harian peserta didik kelas VIII tahun ajaran 2018/2019. Bedasarkan alasan tersebut diperlukan suatu inovasi dalam pembelajaran. Salah satunya adalah pengembagan modul IPA terpadu berbasis inquiry learning pada materi zat aditif makanan di SMP Negeri 1 Sentani, guna mengatasi kesulitan penguasaan konsep dalam meningkatkan keterampilan proses sains berbasis inquiry learning.

Pendekatan pembelajaran inquiry learning adalah pendekatan pembelajaran yang memberi kesempatan pada peserta didik untuk terlibat secara aktif dalam proses pembelajaran melalui penyelidikan, sehingga melatih peserta didik untuk kreatif dan berpikir kritis untuk menemukan sendiri suatu pengetahuan (Siregar. T 2011). Akhir dari metode inquiry learning adalah peserta didik mampu menggunakan pengetahuannya untuk memecahkan permasalahan yang dihadapinya berdasarkan fakta-fakta yang ada peserta didik lebih kreatif dalam pendekatan pembelajaran, (Siregar. T, 2011) ini, diharapkan dapat membuat peserta didik lebih terampil dan meningkat hasil belajarnya (Pengaruh Inquiry Learning Dan Problem-Based Learning Terhadap Hasil Belajar IPA Ditinjau Dari Motivasi Belajar, Handoyono, 2016 ).

Menurut Kalemben. S (2018) menyimpulkan bahwa pembelajaran menggunakan modul IPA terpadu dapat 
meningkatkan keterampilan proses sains peserta didik.

\section{METODE PENELITIAN}

Penelitian ini menggunakan metode penelitian dan pengembangan (Research and Development), untuk menghasilkan produk tertentu dan menguji keefektifan produk tersebut. Produk yang dikembangkan dalam penelitian ini adalah modul IPA terpadu dengan materi zat aditif pada makanan berbasis inquiry learning. Tahap perkembangan modul adalah pendefinisian (Define), Perancangan (Design), Pengembangan (Develop), dan penyebaran (Desseminate), disebut tahaptahap pengembangan model siklus 4D oleh Sugiyono (Puji Rahayu, 2019).

Populasi dalam penelitian ini adalah peserta didik kelas VIII A sampai VIII I SMP Negeri 1 Sentani kabupaten Jayapura. Jumlah populasi adalah 283 peserta didik. Dalam uji coba skala terbatas, uji coba skala luas dan kelas penerapan modul IPA terpadu materi zat aditif makanan dengan model inquiry learning. Sampel adalah peserta didik kelas VIII A yang berjumlah 32 peserta didik.

Instrumen penelitian yang digunakan untuk mengumpulkan data hasi penelitian adalah :

\section{Observasi}

Dilakukan observasi partisipasif, peneliti terlibat langsung dalam proses pembelajaran dan kegiatan keterampilan proses sains terhadap sintaks inquiry learning dalam keaktifan peserta didik.

2. Kuisioner

Kuisioner sebagai penilaian kelayakan produk hasil pengembangan modul IPA terpadu berbasis inquiry learning yang dinilai oleh validator yaitu validasi ahli materi yang terdiri dari aspek kelayakan isi, aspek kebahasaan dan asek penyajian dan penilaian validasi ahli media yaitu aspek kegrafikan. Kuisioner juga diberikan kepada peserta didik dan guru IPA Terpadu SMP Negeri 1 Sentani, untuk mengetahui tanggapan terhadap modul IPA Terpadu yang dikembangkan. Kuisioner penilaian keterampilan proses sains yang diberikan kepada peserta didik sebelum dan sesudah menggunakan modul IPA Terpadu pada proses pembelajaran. Instrumen kuisioner disusun menggunakan skala Likert dimodifikasi.

3. Wawancara

Wawancara dilakukan untuk memperoleh data tanggapan peserta didik dan tanggapan guru IPA Terpadu SMP Negeri 1 Sentani terhadap modul IPA Terpadu yang dikembangkan dalam pembelajaran.

Analisis instrumen yang dilakukan yaitu analisis deskriptif persentase, untuk menganalisa penilaian kelayakan modul oleh validator ahli materi dan validator ahli media, tanggapan peserta didik serta tanggapan guru IPA Terpadu SMP Negeri 1 Sentani pada proses pembelajaran dalam 
Jurnal Ilmu Pendidikan Indonesia 9 (2) : 61 - 67 | 65

menganalisa keaktifan dan keterampilan proses sains (KPS) peserta didik. Menggunakan rumus :

$$
\mathrm{P}=\frac{f}{N} \times 100 \%
$$

Keterangan : $\mathrm{P}=$ Persentase skor penilaian, $\mathrm{f}=$ Jumlah skor yang diperoleh, $\mathrm{N}=$ Jumlah skor maksimal.

\section{HASIL DAN PEMBAHASAN}

Cara Membuat Modul IPA Terpadu Berbasis Inquiry Learning pada Materi Zat Aditif Makanan Pada Proses Pembelajaran IPA Terpadu Peserta Didik Kelas VIII SMP Negeri 1 Sentani

Cara membuat modul IPA terpadu berbasis inquiry learning pada materi zat aditif makanan pada proses pembelajaran IPA terpadu peserta didik kelas VIII SMP Negeri 1 Sentani melalui tujuh tahap yaitu analisis kebutuhan modul, mendesain modul, implementasi, penilaian, evaluasi, validasi dan jaminan kualitas modul dengan menggunakan empat komponen modul yaitu bagian pembuka, pendahuluan, pembelajaran dan evaluasi.

Kelayakan Pengembangan Modul IPA Terpadu Berbasis Inquiry Learning pada Materi Zat Aditif Makanan Pada Proses Pembelajaran IPA Terpadu Peserta Didik Kelas VIII SMP Negeri 1 Sentani

Penilaian kelayakan modul IPA Terpadu yang diberikan oleh tiga validator yaitu validator ahli materi memperoleh rata-rata presentase penilaian sebesar 97,09\% (sangat layak). Hasil validasi yang dilakukan oleh ahli media memperoleh rata - rata presentase penilaian sebesar $96,90 \%$ (sangat layak). Tanggapan guru IPA SMP Negeri 1 Sentani terhadap modul diperoleh rata-rata $93,50 \%$ dengan kategori sangat baik dan tanggapan peserta didik terhadap modul diperoleh rata-rata $91,54 \%$ dengan kategori sangat baik, hal ini diperoleh ratarata keseluruhan sebesar 94,76\% menunjukkan bahwa modul sangat layak untuk diterapkan dalam proses pembelajaran. Berdasarkan penilaian yang telah dilakukan pada penelitian, diketahui bahwa modul sangat layak untuk digunakan dalam proses pembelajaran di kelas VIII SMP Negeri 1 Sentani dengan memanfaatkan lingkungan sekolah sebagai media pendukung dalam kegiatan pembelajaran peserta didik, sehingga terjadi pembelajaran secara kontekstual .

Peningkatan Keterampilan Proses Sains Peserta Didik Kelas VIII SMP Negeri 1 Sentani Melalui Pengembangan Modul IPA Terpadu Berbasis Inquiry Learning pada Materi Zat Aditif Makanan

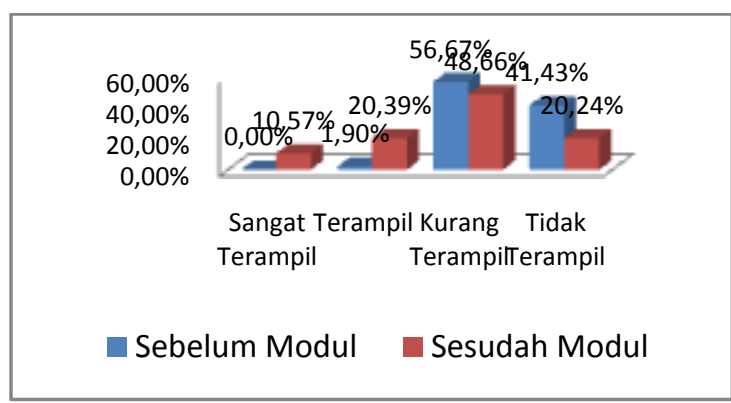

Gambar 1. Diagram Batang Persentase Penilaian KPS Sebelum dan Sesudah Penggunaan Modul IPA Terpadu

Berdasarkan Gambar 1 menunjukkan bahwa secara keseluruhan penilaian keterampilan proses sains (KPS) peserta 
didik menunjukkan adanya peningkatan disetiap kegiatan pembelajaran menggunakan modul IPA terpadu. Persentase peserta didik sebelum menggunakan modul IPA terpadu terlihat belum ada yang terampil, setelah menggunakan modul IPA terpadu diperoleh sangat terampil (10,57\%), terampil (20,39\%), kurang terampil $(48,66 \%)$ dan tidak terampil $(20,24 \%)$. Hal ini sejalan dengan hasil penelitian dari Kalemben. S (2018) menyimpulkan bahwa pembelajaran menggunakan modul IPA terpadu dapat meningkatkan keterampilan proses sains peserta didik. Hasil penelitian tersebut juga diperkuat oleh Siregar $\mathrm{T}$ (2019), bahwa penggunaan modul dapat meningkatkan hasil belajar peserta didik.

\section{SIMPULAN}

Modul IPA terpadu berbasis inquiry learning dapat meningkatkan keterampilan proses sains (KPS) peserta didik kelas VIII SMP Negeri 1 Sentani, setelah menggunakan modul IPA Terpadu diperoleh nilai rata-rata persentase KPS peserta didik sebesar $69,75 \%$ dengan kategori terampil.

\section{SARAN}

Modul IPA Terpadu berbasis inquiry learning dapat digunakan untuk meningkatkan keterampilan proses sains (KPS) peserta didik.

\section{UCAPAN TERIMA KASIH}

Kepala sekolah SMP Negeri 1 Sentani yang telah memberikan dukungan dan kerjasamanya dengan Program studi S2 Pendidikan IPA Uncen dalam pelaksanaan penelitian ini.

\section{DAFTAR PUSTAKA}

Andriani, P. M. (2019). Pemanfaatan Tumbuhan Sebagai Zat Aditif Makanan Oleh Masyarakat Desa Rasau Jaya Umum Kabupaten Kubu Raya. Jurnal Pendidikan Matematika dan IPA, 74-87;

Depdiknas. (2013). Undang-Undang RI Nomor 20 Tahun 2003, Tentang pendidikan Nasional. Jakarta: Biro Hukum Sekjen Depdiknas cet. 1;

Handoyono, N. A. (2016). Pengaruh Inquiry Learning Dan Problem Based Learning Terhadap Hasil Belajar PKKR Ditinjau Dari Motivasi Belajar. Jurnal Pendidikan Vokasi, 32-42;

Huda, F. A. (2018, Maret 8). Pengertian dan Langkah-Langkah Model Pembelajaran Inquiry (Inquiry Learning). Retrieved Februari 2020, 14, from Fatkhan.Web.ID: http://fatkhan.web.id/pengertiandan-langkah langkah-modelpembelajaran-inkuiri-inquirylearning;

Kalemben, S., Rumahorbo., B dan Sallagan, J. (2018). Pengembangan Modul IPA Terpadu Berbasis Inkuiri Terbimbing Untuk Meningkatkan Keterampilan roses Sains, Minat Dan Hasil Belajar peserta Didik Pada Materi Fotosintesis di Kelas VIII SMP Negeri 9 Jayapura. Jurnal Ilmu Pendidikan Indonesia, Vol 6, No 3, Hal 62-70; 
Kemendikbud. (2013). Sistem Pendidikan Nasional. Retrieved from http://lppks.kemdikbud.go.id/uploa ds/pengumuman/uu_no_20_tahun_ 2003.pf ;

Rahayu, P. (2019). Pengembangan Modul IPA berbasis Discovery Learning dalam Meningkatkan Keaktifan, Keterampilan Proses Dan Hasil Belajar Peserta Didik Pada Materi Getaran, Gelombang dan Bunyi Kelas VIII SMP YPK 2 Manokwari. Jurnal Ilmu Pendidikan Indonesia, Vol 8, No 2, Hal 95-10;

Siregar, T, (2011). Upaya Meningkatkan Hasil Belajar Kimia Melalui Model Pembelajaran dengan Pendekatan Inquiry Based Learning (IBL) . Jurnal Prosiding Seminar Nasional;
Siregar, T. (2011). Pendekatan inquiry Based Learning (IBL) mengubah paradigma pembelajaran menjadi inovatif. Jayapura: Logoz Publishing;

Siregar, T. (2019). Modul pembelajaran inkuiri terbimbing pada materi larutan elektrolit dan non elektrolit. Jurnal Ilmu Pendidikan Indonesia, Vol 1, No 1, Hal 8-16. 